\title{
Occurrence of selected bacteria in periodontal pockets of various depths in chronic and aggressive periodontitis
}

\section{Występowanie wybranych periopatogenów w kieszonkach przyzębnych różnej głębokości w przewlekłym i agresywnym zapaleniu przyzębia}

\author{
Agata Orzechowska ${ }^{A-D}$, Ewa Grabowska ${ }^{C}$, Paweł Plakwicz ${ }^{D, E}$, Renata Górska ${ }^{A, C, E, F}$ \\ Department of Periodontology and Oral Diseases, Medical University of Warsaw, Warszawa, Poland \\ A - research concept and design; $\mathrm{B}$ - collection and/or assembly of data; $\mathrm{C}$ - data analysis and interpretation; \\ $D$ - writing the article; $E$ - critical revision of the article; $F$ - final approval of the article
}

Address for correspondence

Agata Orzechowska

E-mail: agata.j.orzechowska@gmail.com

\section{Funding sources}

None declared

Conflict of interest

None declared

Received on November 12, 2017

Reviewed on November 22, 2017

Accepted on November 24, 2017

DOI

$10.17219 / \mathrm{dmp} / 80774$

Copyright

○ 2017 by Wroclaw Medical University

and Polish Dental Society

This is an article distributed under the terms of the

Creative Commons Attribution Non-Commercial License

(http://creativecommons.org/licenses/by-nc-nd/4.0/)

\begin{abstract}
Background. Periodontitis has a complex etiology, with bacteria constituting the main etiological factor. It is not a classic infectious disease, because it is not caused by a specific pathogen. Instead, it is caused by a shift in the microbiological composition, so that the microorganisms, which physiologically inhabit the oral cavity, become pathogenic.

Objectives. The aim of this study is to discuss whether the presence of specific bacteria depends on the form of the disease or on the depth of the periodontal pocket.

Material and methods. The study included 60 patients with chronic or aggressive periodontitis. Periodontal parameters were evaluated and the microbiological material from periodontal pockets was collected.

Results. Porphyromonas gingivalis occurred more frequently in patients with chronic periodontitis, Aggregatibacter actinomycetem comitans was observed only in patients with aggressive periodontitis. The occurrence of Treponema denticola and Aggregatibacter actinomycetemcomitans differed depending on the pocket depth.

Conclusions. The bacterial spectrum and count is not directly related to the pocket depth, so it is not only an effect of the disease progression. Although some relations between bacterial species and particular forms of periodontitis have been observed, they cannot constitute the basis of the diagnosis and differentiation between chronic and aggressive periodontitis. Microbiological testing of the subgingival biofilm would gain more value if extended to studies related to antibodies to selected bacteria.
\end{abstract}

Key words: chronic periodontitis, aggressive periodontitis, Porphyromonas gingivalis, Aggregatibacter actinomycetemcomitans, pocket depth

Słowa kluczowe: przewlekłe zapalenie przyzębia, agresywne zapalenie przyzębia, Porphyromonas gingivalis, Aggregatibacter actinomycetemcomitans, głębokość kieszonek 
Periodontitis has a complex etiology, with bacteria constituting the main etiological factor. It is not a classic infectious disease, because it is not caused by a specific pathogen. Instead, it is caused by a shift in the microbiological composition, so that the microorganisms, which physiologically inhabit the oral cavity, become pathogenic. Moreover, bacteria are responsible only for initiating the disease, whereas tissue destruction depends on host defense, further modified by genetic and environmental factors. ${ }^{1}$

The oral cavity is normally colonized by approximately 700 bacterial species. ${ }^{2,3}$ Some of them remain in an unbound form, the so-called plankton, others colonize the surfaces of hard and soft tissues forming a biofilm. Despite such a vast diversity of species inhabiting the oral cavity, biofilm colonization by various species is not a random process. The order and degree of colonization demonstrate certain patterns. Socransky et al. isolated 40 bacteria and, on the basis of their metabolic preferences, divided them into 5 complexes conventionally marked with colors: yellow, purple, orange, red and green. ${ }^{4}$ These complexes differ mainly in the pathogenicity of constituent bacteria and the order of tissue colonization. The best-described periopathogens include 3 red complex bacteria: Porphyromonas gingivalis (P. gingivalis), Treponema denticola (T. denticola), Tannerella forsythia (T. forsythia) and one of the green complex - Aggregatibacter actinomycetemcomitans (A. actinomycetemcomitans).

The periodontal pocket is a reservoir of periopathogens. An increase of its depth leads to the change of the environment from aerobic to anaerobic and a change in metabolism conditions, which leads to a gradual colonization of subgingival biofilm by other bacterial species. According to Socransky, the composition of newly formed biofilm in gingival pockets $2-3 \mathrm{~mm}$ deep differs from that of mature biofilm in pockets $5 \mathrm{~mm}$ or $10 \mathrm{~mm}$ deep. ${ }^{4}$ The issue that so far has not been clearly explained and attracts a lot of attention in current studies is the extent to which bacteria, in quantitative and qualitative terms, are responsible for the development of periodontitis. Furthermore, it is necessary to explain to what extent their presence or increased numbers results from the disease itself, i.e. the emergence of deeper periodontal pockets constituting a perfect niche for development. Moreover, there is another valid question of high clinical importance: whether the occurrence or increased numbers of specific bacterial species vary depending on the form of periodontitis. The possibility of differentiating particular forms of periodontitis by specific bacteria identification would be a great facilitation in clinical practice as there are no explicit criteria that determine the diagnosis. Yet, recent studies are inconclusive whether the presence and number of specific bacteria is related straight to each periodontits form or is it just an effect of the emergence of deep periodontal pockets.

The aim of the study was to assess the total number of bacteria as well as the presence and number of various species depending on the periodontal pocket depth and on diagnosis.

\section{Material and methods}

The study group consisted of 60 individuals referred to the Department of Periodontology in Warszawa between October 2013 and December 2014. The patients were divided into 2 groups depending on the diagnosis - 30 patients with chronic periodontits (CP) and another 30 patients with aggressive periodontits (generalized AgP). The diagnosis was based on clinical and radiological examination according to AAP classification. ${ }^{5}$

Inclusion criteria for the study were: active, untreated periodontitis and presence of at least one pocket $5 \mathrm{~mm}$ deep and one periodontal pocket of $7 \mathrm{~mm}$ or deeper. Exclusion criteria for the study were: a coexisting general disease that might affect the course of periodontal disease, chronic intake of drugs that could modify the course of periodontal disease (antibiotics, steroids, anti-inflammatory, immunosuppressive and antiepileptic drugs, calcium channel blockers) within 6 months prior to the study, pregnancy, smoking (both active and past), current orthodontic treatment, scaling within 6 months prior to the study, and topical application of antibacterial or bacteriostatic agents within 6 months preceding the study.

The study group included 26 males and 34 females. Among the patients diagnosed with generalized AgP, 70\% were females, while among the subjects with the CP, $43.3 \%$ were females. The mean age was 30.7 years, and 56.9 years for patients with generalized AgP and CP, respectively.

The study consisted of a clinical and a laboratory examination. The clinical part included general and dental history, periodontal measurements including hygiene indices - Plaque Index (PI), and API, bleeding index - BOP, pocket depth - PD, clinical attachment level - CAL, and samples of microbiological material from selected periodontal pockets. ${ }^{6-8}$ The bacterial DNA testing from the gingival cervical fluid (GCF) using real-time polymerase chain reaction (PCR) was performed. Ready-made PET diagnostic kits by MIP Pharma (PET ${ }^{\circledR}$ Plus Kit, MIP Pharma, Germany) consisted of sterile paper-points, color-marked vials and transport box. According to the manufacturer's recommendations, after isolating the examined pockets from, dental plaque was removed from the gingival margin with a cotton swab, then the area was dried. Sterile tweezers were used to place one paper-point in each of the 2 selected periodontal pockets, one $5 \mathrm{~mm}$ deep, the other $\geq 7 \mathrm{~mm}$ deep (the deepest one for the patient was chosen). The paper-points were placed full depth in periodontal pockets for $20 \mathrm{~s}$, then removed and immediately packed in individual, labeled vials and later sent to the manufacturer's laboratory.

The laboratory part of the examination aimed at a quantitative and qualitative identification of bacteria in the collected material. Using polymerase chain reaction (Real Time PCR) the total bacteria count in the sample and the numbers of an individual species, selected for purpose of the study ( $P$. gingivalis, $T$. denticola and A. actinomycetemcomitans), were recorded. 
The following tests were used for statistical analysis: the Mann-Whitney test for continuous variables, the Spearman rank correlation test and the Wilcoxon test for dependent samples, the $\chi^{2}$ test for categorical variables. Linear regression was used for multivariable analysis. The threshold of statistical significance was assumed at $\mathrm{p}=0.05$.

The study received consent of the Bioethic Comission of Medical University of Warsaw.

\section{Results}

\section{Results of periodontal examination}

Depending on the diagnosis, statistically significant differences concerning patients' gender and age were observed. Seventy percent and $43.3 \%$ of the patients were females among with generalized AgP and CP, respectively. The mean age of patients with generalized AgP was significantly lower (30.7 years) compared with patients with CP (56.9 years).

Statistically significant differences in the average PI and API indices were observed between generalized AgP and $\mathrm{CP}$ groups. These values were significantly lower among patients with generalized AgP (PI: 86.2\%, 61.9\% in CP, API: $93.8 \%$ in generalized AgP, 74.4\% in CP).

Mean values of BOP and PD measurements demonstrated no significant differences between patients with generalized AgP and CP, whereas mean CAL was significantly higher in patients with CP, when compared with generalized AgP (4.7 mm and. $3.4 \mathrm{~mm}$, respectively).

Significant differences were observed between the total number of teeth. In the patients with CP the median was significantly lower (22 teeth) compared to patients with the generalized AgP (29 teeth) (Table 1).

\section{Results of microbiological assessment}

No statistically significant differences were noted between the total number of bacteria depending on the PD, both for the entire study group as well as for individual $\mathrm{CP}$ and generalized AgP groups. High variability of this parameter was observed in all groups (Table 2).

Table 1. Group characteristics

\begin{tabular}{|c|c|c|c|}
\hline Parameters & $\begin{array}{c}\text { Chronic } \\
\text { periodontitis } \\
n=30 \\
\text { mean }( \pm S D)\end{array}$ & $\begin{array}{c}\text { Aggressive } \\
\text { periodontitis } \\
n=30 \\
\text { mean }( \pm S D)\end{array}$ & $\begin{array}{l}\text { Comparison } \\
\text { (Mann-Whitney } \\
\text { test) }\end{array}$ \\
\hline Age - years & $56.9( \pm 8.9)$ & $30.7( \pm 5.9)$ & $p<0.0001$ \\
\hline Plaque Index - \% & $86.2( \pm 16.4)$ & $61.9( \pm 24.4)$ & $p=0.0001$ \\
\hline API - \% & $93.8( \pm 13.4)$ & $74.4( \pm 25.3)$ & $p=0.0014$ \\
\hline BOP - \% & $81.5( \pm 18.3)$ & $80.4( \pm 21.5)$ & $p=0.9463$ \\
\hline$P D-m m$ & $4.0( \pm 0.7)$ & $4.1( \pm 1.1)$ & $p=0.7282$ \\
\hline$C A L-m m$ & $4.7( \pm 1.3)$ & $3.4( \pm 1.7)$ & $p=0.0006$ \\
\hline Number of teeth & $21( \pm 5.4)$ & $28.5( \pm 3.2)$ & $p<0.0001$ \\
\hline
\end{tabular}

Table 2. Total numbers of bacteria depending on periodontal pocket depth and diagnosis

\begin{tabular}{|l|c|c|c|}
\multicolumn{1}{|c|}{ Parameters } & $\begin{array}{c}\text { Bacterial count } \\
\text { in patients } \\
\text { with CP } \\
\mathrm{n} \times 10^{3}( \pm \mathrm{SD})\end{array}$ & $\begin{array}{c}\text { Bacterial count } \\
\text { in patients } \\
\text { with AgP } \\
\mathrm{n} \times 10^{3}( \pm \mathrm{SD})\end{array}$ & $\begin{array}{c}\text { Comparison } \\
\text { according } \\
\text { to diagnosis } \\
\text { (Mann-Whitney } \\
\text { test) }\end{array}$ \\
\hline $\mathrm{PD}=5 \mathrm{~mm}$ & $10.4( \pm 27.3)$ & $9.5( \pm 16.8)$ & $\mathrm{p}=0.9646$ \\
$\mathrm{PD} \geq 7 \mathrm{~mm}$ & $13( \pm 18.3)$ & $8.1( \pm 13.6)$ & $\mathrm{p}=0.3951$ \\
$\begin{array}{l}\text { Comparison depen- } \\
\text { ding on pocket depth } \\
\text { (Wilcoxon test for } \\
\text { dependent samples) }\end{array}$ & $\mathrm{p}=0.0656$ & $\mathrm{p}=0.9344$ & - \\
\hline
\end{tabular}

The presence of Porphyromonas gingivalis was observed in $44(73.3 \%)$ patients (in $53.3 \%$ of patients with generalized AgP and in 93.3\% of patients with CP). The differences were statistically significant. In pockets of $5 \mathrm{~mm}$ and pockets $\geq 7 \mathrm{~mm}$, the occurrence of $P$. gingivalis was significantly more frequent among patients with CP $(80 \%$ and $86.7 \%, 43.3 \%$ and $53.3 \%$ in generalized AgP). However, there were no significant correlations between the prevalence of $P$. gingivalis and the pocket depth in the entire study group, as well as in the generalized AgP and in CP groups. The presence and number of $P$. gingivalis was significantly higher in patients with $\mathrm{CP}$, both in pockets $5 \mathrm{~mm}$ and $\geq 7 \mathrm{~mm}$ deep (on average 123.1 and $157.4 \times 10^{3}$, 72 and $139.9 \times 10^{3}$ in generalized AgP). None of the study groups demonstrated any correlation between the number and the depth of pockets (Table 3).

The presence of $T$. denticola was observed in 54 (90\%) of all patients. The occurrence was comparable between $\mathrm{CP}$ and generalized AgP patients, whereas there was no correlation with PD. Among patients generalized AgP, the number of $T$. denticola was statistically significantly higher in deep pockets $\left(28.8 \times 10^{3}\right.$ and $0.43 \%$ vs $32 \times 10^{3}$ and $0.58 \%$ ) (Table 4 ).

The presence of $A$. actinomycetemcomitans was found only in patients with generalized AgP. The number of $A$. actinomycetemcomitanswas statistically significantly higher in pockets $5 \mathrm{~mm}$ deep (Table 5).

\section{Discussion}

The role of bacteria in the etiology of periodontitis is undeniable. They influence the periodontal tissues directly (by the use of toxins) and indirectly (by the immune system activation). It is proven that some bacteria species occur in higher numbers in patients with periodontits. Recent studies reveal that different types of bacteria may occur in different forms of the disease. It is still not certain whether bacterial spectrum changes due to the pocket depth and has no relation to the form and stage of the disease or if the occurrence and number of particular microorganisms are precisely related with the diagnosis. The link between the type of periodontitis and bacteria species could be an important diagnostic tool. 
Table 3. Occurrence and numbers of Porphyromonas gingivalis depending on periodontal pocket depth and diagnosis

\begin{tabular}{|c|c|c|c|c|}
\hline $\begin{array}{l}\text { Occurence/ } \\
\text { /Numbers }\end{array}$ & Parameters & Patients with $\mathrm{CP}$ & Patients with AgP & $\begin{array}{c}\text { Comparison according to } \\
\text { diagnosis (Mann-Whitney test }\end{array}$ \\
\hline \multirow{3}{*}{ Occurence } & total; n (\%) & $28(93.3 \%)$ & $16(53.3 \%)$ & $p=0.0013^{*}$ \\
\hline & $\mathrm{PD} \geq 7 \mathrm{~mm} ; \mathrm{n}(\%)$ & $26(86.7 \%)$ & $16(53.3 \%)$ & $p=0.0112^{*}$ \\
\hline & comparison depending on pocket depth* & $p=0.7290$ & $p=0.6054$ & - \\
\hline \multirow{4}{*}{ Number } & $\mathrm{PD}=5 \mathrm{~mm} ; \mathrm{n} \times 10^{3}( \pm \mathrm{SD})$ & $123.1( \pm 329)$ & $72.0( \pm 183.1)$ & $p=0.0243$ \\
\hline & $\mathrm{PD} \geq 7 \mathrm{~mm} ; \mathrm{n} \times 10^{3}( \pm \mathrm{SD})$ & $157.4( \pm 298)$ & $139.9( \pm 340.7)$ & $p=0.0309$ \\
\hline & comparison depending on pocket depth** & $p=0.0856$ & $p=0.2052$ & - \\
\hline & correlation between level in pockets $5 \mathrm{~mm}$ deep and $\geq 7 \mathrm{~mm}$ & $\begin{array}{l}r=0.56 \\
p=0.0013\end{array}$ & $\begin{array}{l}r=0.78 \\
p<0.0001\end{array}$ & - \\
\hline
\end{tabular}

${ }^{*}-\chi^{2}$ test, $^{* *}-$ Wilcoxon test for dependent samples, ${ }^{* * *}-$ Spearman test.

Table 4. Occurrence and numbers of Treponema denticola depending on periodontal pocket depth and diagnosis

\begin{tabular}{|c|c|c|c|c|}
\hline $\begin{array}{l}\text { Occurence/ } \\
\text { /Numbers }\end{array}$ & Parameters & Patients with CP & Patients with AgP & $\begin{array}{c}\text { Comparison according to } \\
\text { diagnosis (Mann-Whitney test) }\end{array}$ \\
\hline \multirow{5}{*}{ Occurence } & total, n (\%) & $28(93.3 \%)$ & $26(86.7 \%)$ & $p=0.6670 *$ \\
\hline & $\mathrm{PD}=4-6 \mathrm{~mm}, \mathrm{n}(\%)$ & $22(73.3 \%)$ & $20(66.7 \%)$ & $p=0.7782^{*}$ \\
\hline & $\mathrm{PD} \geq 7 \mathrm{~mm}, \mathrm{n}(\%)$ & $27(90.0 \%)$ & $26(86.7 \%)$ & $p=1.0000^{*}$ \\
\hline & comparison depending on pocket depth ( $\chi^{2}$ test) & $p=0.1820$ & $p=0.1270$ & - \\
\hline & correlation between presence in pockets $4-6 \mathrm{~mm}$ deep and $\geq 7 \mathrm{~mm} *$ & $p=0.3354$ & $p=0.0136$ & - \\
\hline \multirow{4}{*}{ Number } & $P D=4-6 \mathrm{~mm} ; \mathrm{n} \times 10^{3}( \pm \mathrm{SD})$ & $41.0( \pm 132.6)$ & $28.8( \pm 118.1)$ & $p=0.3374$ \\
\hline & $\mathrm{PD} \geq 7 \mathrm{~mm} ; \mathrm{n} \times 10^{3}( \pm \mathrm{SD})$ & $44.5( \pm 72.5)$ & $32.0( \pm 68)$ & $p=0.2278$ \\
\hline & comparison depending on pocket depth** & $p=0.0776$ & $p=0.0271$ & - \\
\hline & correlation between number in pockets $4-6 \mathrm{~mm}$ deep and $\geq 7 \mathrm{~mm}$ *** & $\begin{array}{l}r=0.37 \\
p=0.0458\end{array}$ & $\begin{array}{l}r=0.38 \\
p=0.0382\end{array}$ & - \\
\hline
\end{tabular}

* $-\chi^{2}$ test, ${ }^{* *}-$ Wilcoxon test for dependent samples, ${ }^{* * *}-$ Spearman test.

Table 5. Occurrence and numbers of Aggregatibacter actinomycetemcomitans depending on periodontal pocket depth and diagnosis

\begin{tabular}{|c|c|c|c|c|}
\hline $\begin{array}{l}\text { Occurence/ } \\
\text { /Numbers }\end{array}$ & Parameters & Patients with $\mathrm{CP}$ & Patients with AgP & $\begin{array}{c}\text { Comparison according to } \\
\text { diagnosis (Mann-Whitney test) }\end{array}$ \\
\hline \multirow{5}{*}{ Occurence } & total & 0 & $11(36.7 \%)$ & $p=0.0008^{*}$ \\
\hline & $\mathrm{PD}=5 \mathrm{~mm}, \mathrm{n}(\%)$ & 0 & $10(33.3 \%)$ & $p=0.0018^{*}$ \\
\hline & $\mathrm{PD} \geq 7 \mathrm{~mm}, \mathrm{n}(\%)$ & 0 & $6(20.0 \%)$ & $p=0.0314^{*}$ \\
\hline & comparison depending on pocket depth* & $\mathrm{n} / \mathrm{a}$ & $p=0.3811$ & - \\
\hline & correlation between level in pockets $4-6 \mathrm{~mm}$ deep and $\geq 7 \mathrm{~mm} *$ & $\mathrm{n} / \mathrm{a}$ & $p=0.0155$ & - \\
\hline \multirow{4}{*}{ Number } & $\mathrm{PD}=5 \mathrm{~mm} ; \mathrm{n} \times 10^{3}( \pm \mathrm{SD})$ & 0 & $3.69( \pm 9.70)$ & $p=0.0007$ \\
\hline & $\mathrm{PD} \geq 7 \mathrm{~mm} ; \mathrm{n} \times 10^{3}( \pm \mathrm{SD})$ & 0 & $0.77( \pm 3.13)$ & $p=0.0110$ \\
\hline & comparison depending on pocket depth ${ }^{* *}$ & $\mathrm{n} / \mathrm{a}$ & $p=0.0367$ & - \\
\hline & correlation between level in pockets $5 \mathrm{~mm}$ deep and $\geq 7 \mathrm{~mm}{ }^{* * *}$ & $\mathrm{n} / \mathrm{a}$ & $\begin{array}{l}r=0.59 \\
p=0.0006\end{array}$ & - \\
\hline
\end{tabular}

${ }^{*}-\chi^{2}$ test, ${ }^{* *}-$ Wilcoxon test for dependent samples, ${ }^{* * *}-$ Spearman test.

Characteristics of the study group reflect the criteria used to distinguish chronic and aggressive periodontitis. The average age of patients with aggressive periodontitis was statistically lower than in patients with chronic form (respectively 30.9 and 56.9 years). Faveri et al. also observed statistically significant differences between the age of patients with aggressive and chronic periodontitis, reporting the mean values of 25.2 and 42 years respec- tively. ${ }^{9}$ Riep et al. reported that the average age of patients with aggressive and chronic periodontitis was 34.4 and 55.2 years, respectively. ${ }^{10}$ These results indirectly confirmed the typical, early onset of aggressive periodontitis. The age at the onset, although not considered in the official primary and secondary characteristics, constitutes an important parameter for the diagnosis and differentiation of aggressive periodontitis. Certainly, it cannot be the 
single criterion for making the diagnosis, because it is not always possible to determine the age at the onset of symptoms, and the patient's age at the time of examination has no diagnostic value. It is necessary to analyze other clinical parameters, which together constitute the clinical picture of the disease.

Significant differences in the oral hygiene indices confirmed that the oral hygiene might be a key parameter differentiating chronic and aggressive periodontitis. Important differences referred to both simplified plaque index and to approximal plaque index, achieving significantly lower average values among patients with generalized AgP. The concurrent lack of differences between mean values of $\mathrm{PD}$ and $\mathrm{BOP}$ and between individuals with $\mathrm{CP}$ and generalized AgP confirmed different ethiopathogenesis of these two forms. Similar values of parameters indicating active inflammation, despite significant differences in the status of oral hygiene, emphasized a major role of the immunoinflammatory response in the course of aggressive periodontitis. They also confirmed that one of the primary features of generalized AgP, oral hygiene disproportionate to the severity of the disease, is a characteristic of real diagnostic value. These findings were reflected in studies by other authors., ${ }^{9,11}$

No reports on significant differences regarding CAL in generalized AgP and CP groups have been previously described in the literature. In the study, statistically significant differences in CAL between individuals with CP and generalized AgP were most likely associated with disease duration. This relationship was statistically insignificant ( $\mathrm{p}=0.815$ and $\mathrm{p}=0.0006)$ after adjusting for age in multivariate analysis. This means that after adjusting for age, the mean CAL did not vary depending on the diagnosis.

Significant differences regarding the gender of patients (43.3\% of females in the CP group and $70 \%$ of females in the generalized AgP group) may suggest a higher prevalence of the aggressive form in women. Only a few studies confirmed this relationship. In 2002 Cortelli et al. studied 600 patients with generalized AgP and observed a positive correlation between females and the prevalence of generalized AgP. ${ }^{12}$ The American Academy of Periodontology did not include the gender among the criteria established for generalized AgP, and most studies denied such a relationship. ${ }^{9,11}$ The group of patients in this study was, however, too small to permit conclusions of epidemiological nature. The fact that $70 \%$ of individuals with diagnosed generalized AgP were females might indicate higher health awareness and better care of oral hygiene when compared to men, especially since they were individuals under 37 years of age, with relatively good oral hygiene, and periodontal tissue destruction was largely a result of immune response disorders. In patients with CP, the major cause of the disease is hygienic negligence. It can be assumed that significant differences regarding gender concerned not so much the presence of particular forms of periodontitis, but rather the need of female patients to be treated.
An analysis of microbial composition in periodontal pockets in patients with CP and generalized AgP did not lead to clear conclusions that could constitute the basis for the differentiation of these two forms.

An assessment of the total number of bacteria in a selected periodontal pocket has no diagnostic value. No significant differences were observed in the numbers of bacteria depending on the pocket depth and on the diagnosis. Moreover, high values of standard deviation, sometimes exceeding the mean values twofold, proved that the variability of bacteria between patients was very high. This means that the total number of bacteria in the subgingival biofilm was typical neither for a specific pocket depth nor for particular forms of periodontitis, but rather constituted an individual feature of the patient. Although the total number of bacteria in pockets $\geq 7 \mathrm{~mm}$ among patients with CP appeared to be higher compared to patients with generalized AgP $\left(13035 \times 10^{3}\right.$ in CP, vs $8188 \times 10^{3}$ in generalized AgP), high variability of these values did not permit us to establish statistical significance.

Previous studies pointed out that initiation and progression of periodontitis was not related to the overall increase in the number of bacteria but to an imbalance in the microbial composition, which was individual for each patient. ${ }^{13,14}$ Recent studies emphasized a special role not of bacteria and not of an increase in their number, but in their percentage, i.e. in the change of proportions of the microbial composition. In the present study, numerous significant correlations were observed between the presence and the number of individual periopathogens depending on initial diagnosis, as well as on the pocket depth.

The presence of particular pathogens was not related to the pocket depth; it was comparable in pockets both $5 \mathrm{~mm}$ and $\geq 7 \mathrm{~mm}$ deep. Similar findings were reported in a study on 58 patients. ${ }^{15}$ A similar occurrence of specific pathogens in pockets $\geq 4 \mathrm{~mm}$ was observed: T. denticola in $82.7 \%$, P. gingivalis in $72.4 \%$, and - least frequently $-A$. actinomycetemcomitans in $29.9 \%$ of individuals. In a study on 34 patients with periodontitis and pockets deeper than $5 \mathrm{~mm}^{16}$. T. denticola was observed in $88.2 \%$, $P$. gingivalis in $50 \%$ of patients, whereas $A$. actinomycetemcomitans in $23.3 \%$ - and it was also the least frequent of all selected bacteria. Another study reported A. actinomycetemcomitans in 93\% of patients. Low detection of $A$. actinomycetemcomitans in patients with generalized AgP in the present study might be associated with the bacterial ability to penetrate epithelial and connective tissue. ${ }^{17}$ It may also be attributed to the phenomenon of false negative reading, typical for microorganisms with low occurrence (in case of a small number of examined samples). ${ }^{18}$

A significant difference in the occurrence of periopathogens was observed depending on the diagnosis. P. gingivalis was detected significantly more frequently among patients with CP $(93.3 \%, 53.3 \%$ in generalized AgP). 
A. actinomycetemcomitans was found only in patients with the generalized AgP, but the presence of this pathogen was observed only in 11 of 30 (36.7\%) individuals with generalized AgP. The presence of the $T$. denticola species was comparable in both groups of patients.

In another study, significantly higher incidence of $A$. actinomycetemcomitans among patients with generalized AgP was found; however, no difference was observed between the presence of P.g. and T. denticola among groups. Another study confirmed a higher incidence of $P$. gingivalis among patients with CP and of A. actinomycetemcomitans in patients with generalized AgP, whereas there was no difference in the incidence of T. denticola between two groups of patients. ${ }^{10}$ The authors also emphasized that the pocket depth had a much more significant impact on the occurrence of these pathogens than the form of periodontitis. These correlations were observed especially for $P$. gingivalis and $T$. denticola, and the only pathogen whose presence was not dependent on the pocket depth was $A$. actinomycetemcomitans In the present study, no correlation between the occurrence of any of the tested pathogens and the pocket depth was found.

Although other reports confirmed a significantly higher occurrence of $A$. actinomycetemcomitans in generalized AgP, it was also observed (although less frequently) in patients with CP., unlike in this study. Mombelli et al. found that in 8 of the 11 studies there was an association between the presence of $A$. actinomycetemcomitans and aggressive periodontitis, and in only 7 of them an absence of $A$. actinomycetemcomitans in CP was reported. ${ }^{20}$ Sanz et al. compared a group of 61 patients with CP, 31 individuals from Spain and 30 from the Netherlands. ${ }^{21}$ The results of the study showed significant differences between the groups in terms of the presence of particular bacteria. $P$. gingivalis was observed significantly more frequently in individuals from Spain, whereas A. actinomycetemcomitans in Dutch patients. Furthermore, a significantly higher incidence of $A$. actinomycetemcomitans among patients with generalized AgP does not constitute a rule $(36.7 \%$ according to own research, $47 \%$ according to Kowalski). ${ }^{19}$ Differences in the composition of biofilm may also be associated with race, age or geographical location. In different parts of the world there are significant differences in the microbial composition of periodontal pockets. Therefore, detecting A. actinomycetemcomitans in a diagnosed patient does not permit an explicit identification of aggressive periodontitis. Also, the absence of this pathogen in the tested pocket may not be the basis for excluding generalized AgP.

Results of other studies related to the relationship between the number of individual bacteria and the form of periodontal disease primarily confirm more numerous presence of $A$. actinomycetemcomitans in the course of aggressive periodontitis. ${ }^{11,22-24}$ Many reports also confirmed a greater number of the pathogen in periodontal pockets not exceeding $6 \mathrm{~mm}$ compared to deeper pockets, which is consistent with the results of this study. ${ }^{9,11,12,25}$ Presumably Aggregatibacter actinomycetemcomitans is not sufficiently resistant to conditions prevailing in deep periodontal pockets and to competition of other periopathogens. ${ }^{9,26}$ This confirms the assumption that $A$. actinomycetemcomitans is primarily responsible for starting the disease, whereas its progression involves a broader bacterial spectrum. These findings also have clinical significance. This information should be considered when taking material for microbiological tests, and instead of collecting material intuitively from the deepest pockets, it is worthwhile to take an aggregate sample which would also include pockets not exceeding $6 \mathrm{~mm}$.

Recent studies emphasized that the number of individual periopathogens, which increases with the severity of periodontal disease, was not related to the form of the disease but resulted from the increasing depth of periodontal pockets and their internal conditions which are favorable for some species and unfavorable for others, and from immune response of the host.9,10,27 The present study did not support this theory. The results permit us to assume that the number of bacteria is a value that primarily depends on the patient's predispositions. An assessment of an objective number of bacteria responsible for the onset and progression of periodontal disease is not possible, as it is individual for each patient. While a given number of pathogens will result in increased immune response and large inflammation in one patient, in another it will remain a subthreshold value, not leading to the formation of periodontitis, or leading to its less severe form. Microbiological testing of the subgingival biofilm in the diagnosis and differentiation would undoubtedly gain more value if extended to studies related to antibodies to selected bacteria. This does not mean that microbiological tests themselves have no diagnostic value - certainly, they allow for more accurate selection of chemotherapeutic agents, both topical and general.

Concluding, the bacterial spectrum and count are not directly related to the pocket depth, so it is not only an effect of the disease progression. Although some relations between bacterial species and particular forms of periodontitis have been observed, they cannot constitute the basis of the diagnosis and differentiation.

\section{References}

1. Page RC, Kornman KS. The pathogenesis of human periodontitis: An introduction. Periodontol 2000, 1997;14:9-11.

2. Paster BJ, Boches SK, Galvin JL, et al. Bacterial diversity in human subgingival plaque. J Bacteriol. 2001;183:3770-3783.

3. Berezow AB, Darveau R. Microbial shift and periodontitis. Periodontol 2000. 2011;55:36-47.

4. Socransky SS, Haffajee AD, Cugini MA, Smith C, Kent RL Jr. Microbial complexes in subgingival plaque. J Clin Periodontol. 1998;25:134-144.

5. Armitage GC. Development of a classification system for periodontal diseases and conditions. Ann Periodontol. 1999;4:1-6.

6. O'Leary TJ, Drake RB, Naylor JE. The plaque control record. J Periodontol. 1972;43:38. 
7. Lange DE. Parodontologie in der taglichen Praxis. 3. Aufl. Berlin: Quintessenz, 1986:55-61.

8. Mühlemann HR, Son S. Gingival sulcus bleeding - a leading symptom in initial gingivitis. Helv Odontol Acta. 1971;15:107-113.

9. Faveri M, Figueiredo LC, Duarte PM, Mestnik MJ, Mayer MPA, Feres M. Microbiological profile of untreated subjects with localized aggressive periodontitis. J Clin Periodontol. 2009;36:739-749.

10. Riep B, Edesi-Neuss L, Claessen F, et al. Are putative periodontal pathogens reliable diagnostic markers? J Clin Microbiol. 2009;47:1705-1711.

11. Casarin RCV, Del Peloso Ribeiro E, Mariano FS, Nociti FH Jr, Casati MZ, Goncalves RB. Levels of Aggregatibacter actinomycetemcomitans, Porphyromonas gingivalis, inflammatory cytokines and species-specific immunoglobulin $\mathrm{G}$ in generalized aggressive and chronic periodontitis. J Periodont Res. 2010;45:635-642.

12. Cortelli JR, Cortelli SC, Jordan S, Haraszthy VI, Zambon JJ. Prevalence of periodontal pathogens in Brazilians with aggressive or chronic periodontitis. J Clin Periodontol. 2005;32:860-866.

13. Darveau RP. Periodontitis: A polymicrobial disruption of host homeostasis. Nature Rev Microbiol. 2010;8:481-490.

14. Abusleme L, Dupuy AK, Dutzan N, et al. The subgingival microbiome in health and periodontitis and its relationship with community biomass and inflammation. ISME J. 2013;7:1016-1025.

15. Nędzi-Góra M, Kowalski J, Krajewski J, Górska R. Microbiological analysis of deep periodontal pockets in patients with chronic periodontitis using the PCR method. Czas Stomatol. 2007;60:717-725 [in Polish].

16. Baker M, Myszko-Coelho M, Kozłowski Z, Dominiak M. Molecular evaluation of periodontal pathogens from deep periodontal pockets in the course of advanced periodontitis. Dent Med Probl. 2013;50:197-204 [in Polish].

17. Papapanou PN, Teanpaisan R, Obiechina NS, et al. Periodontal microbiota and clinical periodontal status in a rural sample in southern Thailand. Eur J Oral Sci. 2002;110:345-352.

18. Haffajee AD, Socransky SS. Effect of sampling strategy on the falsenegative rate for detection of selected subgingival species. Oral Microbiol Immunol. 1992;7:57-59.

19. Kowalski J. Genetic and microbiological verification of generalized chronic periodontitis and generalized aggressive periodontitis. Dent Med Probl. 2012;49:370-376 [in Polish].

20. Mombelli A, Casagni F, Madianos PN. Can presence or absence of periodontal pathogens distinguish between subjects with chronic and aggressive periodontitis? A systematic review. J Clin Periodontol. 2002;29:10-21.

21. Sanz M, van Winkelhoff AJ, Herrera D, Dellemijn-Kippuw N, Simón $R$ Winkel E. Differences in the composition of the subgingival microbiota of two periodontitis populations of different geographical origin. A comparison between Spain and The Netherlands. Eur J Oral Sci. 2000;108:383-392.

22. Cortelli JR, Cortelli SC, Pallos D, Jorge AO. Prevalence of aggressive periodontitis in adolescents and young adults from Vale do Paraiba. Pesqui Odontol Bras. 2002;16:163-168.

23. Gajardo M, Silva N, Gomez L. Prevalence of periodontopathic bacteria in aggressive periodontitis patients in a Chilean population. J Periodontol. 2005;76:289-294.

24. Schacher B, Baron F, Roßberg M, Wohlfeil M, Arndt R, Eickholz P. Aggregatibacter actinomycetemcomitans as indicator for aggressive periodontitis by two analyzing strategies. J Clin Periodontol. 2007;34:566-573

25. Yang HW, Huang YF, Chan Y, Chou MY. Relationship of Actinobacillus actinomycetemcomitans serotypes to periodontal condition: Prevalence and proportions in subgingival plaque. Eur J Oral Sci. 2005;113:28-33.

26. Teughels W, Haake SK, Sliepen I, et al. Bacteria interfere with A. actinomycetemcomitans colonization. J Dent Res. 2007;86:611-617.

27. Gatto MR, Montevecchi M, Paolucci M, Landini MP, Checchi L. Prevalence of six periodontal pathogens in subgingival samples of Italian patients with chronic periodontitis. New Microbiol. 2014;37:517-524. 
